\title{
PRESENÇA NIKKEI NO BRASIL: INTEGRAÇÃO E ASSIMILAÇÃO'
}

Alexandre Ratsuo Uehara

RESUMO: Os imigrantes japoneses que vieram no começo do século XX ao Brasil não tinham como objetivo permanecerem no país, no entanto, eles alteraram seus planos. Este texto traz uma avaliação desse processo, tentando entender como foi e como é a inserção dos imigrantes e descentes de japoneses na sociedade brasileira.

PALAVRAS-CHAVE: identidade, japoneses, imigração, assimilação.

ABSTRACT: The Japanese immigrants who came in the early 20th century to Brazil had not aimed to remain here; however, they change their plans. This article provides an evaluation of that process, trying to understand how was and how is the integration of immigrants and descendents of Japanese in the Brazilian society.

KEY WORDS: identity, Japanese, immigration, assimilation.

\section{Introdução}

A identidade dos descendentes de japoneses no Brasil apresenta uma complexa combinação entre ser brasileiro e ser japonês, com nuances e dimensões variadas de influências das duas culturas. A definição dessa composição não é simples nem fácil, pois, ao mesmo tempo, carrega influência das duas culturas e delas se distancia, não permitinđo estabelecer uma regra definitiva sobre a formação das identidades.

1. Texto apresentado no "Simpósio Internacional Comemorativo ao Centenário da Imigração Japonesa no Brasil - CEJAP-USP/NICHIBUNKEN - Sessão: "Recepção e Assimilação da Cultura Japonesa" São Paulo, 16 de Outubro de 2008. 
A identidade formada por essa mistura de influências brasileiras e japonesas é resultante também das experiências e reações individuais. É perceptível também que há um enfraquecimento das heranças culturais e valores japoneses com o avançar das gerações no Brasil. Porém, essa afirmação também é relativa, pois a própria cultura japonesa se modifica, o seu conteúdo trazida pelos imigrantes no período pré Segunda Guerra Mundial e transmitida no Brasil é diferente da cultura contemporânea em muitos aspectos.

Portanto, tanto a cultura como a formação da identidade são elementos dinâmicos. Stuart Hall, professor e fundador da Center for Contemporary Cultural Studies da Universidade de Birmingham, afirma que não só a formação da identidade é variável, como a identidade de um mesmo indivíduo se transforma ao longo do tempo.

"O sujeito assume diferentes identidades em diferentes momentos, identidades que não são unificadas ao redor de um 'eu' coerente. Dentro de nós há identidades contraditórias, empurrando em diferentes direções, de tal modo que nossas identificações estão continuamente deslocadas ... A identidade plenamente unificada, completa, segura e coerente é uma fantasia" (HALL, 2003, p.13).

Esse raciocínio ajuda a entender, particularmente, a identidade dos indivíduos pósmodernos e é uma possibilidade para o entendimento do porque um nikkei no Brasil pode se sentir japonês, mas depois de um período de vivência no Japão se descobrir brasileiro. Ou, mesmo não indo ao Japão, a relação da população nikkei - composta de imigrantes e descendentes de japoneses, independente da geração - com a sociedade brasileira é dinâmica e conduz a questões como:

a) Está havendo um processo de assimilação? Há argumentos nesse sentido baseados, por exemplo, no fato da diminuição da participação do nikkei nas organizações e associações culturais japonesas.

b) Como explicar o complexo dilema entre e dentro os nipo-brasileiros, que não admitem ser uma simples identificação de diáspora do Japão, mas que também se percebem como distintos dos brasileiros típicos? (LESSER, 2008, p. 179).

Este texto buscará reconstruir o processo da emigração do Japão, mostrando suas causas e fatores que contribuíram para o seu direcionamento para o Brasil no início do século XX e discorrerá sobre a interação dos imigrantes japoneses que vieram ao país e de seus descendentes na sociedade brasileira.

\section{Introdução histórica à imigração}

O Japão viveu um longo período de isolamento internacional no qual o relacionamento do país era restrito às trocas comerciais com a Holanda pelo porto de 
Dejima, em Nagasaki. O processo de internacionalização do país passou a ocorrer a partir de 1853, quando foi obrigado, por ameaças de ataque da frota militar dos EUA comandada pelo Comodoro Perry, a se abrir ao comércio internacional. Essa abertura dos portos proporcionou oportunidades de emigração aos japoneses, que iniciaram a busca por melhores oportunidades de realização econômica no exterior. Isso porque no período de isolamento do Shogunato de Tokugawa o governo não permitia que seus cidadãos emigrassem. Houve somente a saída de alguns estudantes que receberam permissões especiais de longo prazo, alguns refugiados políticos e passageiros clandestinos em navios, totalizando números despreziveis se comparado com o êxodo a partir da Restauração Meiji (ONOZAWA, 2003, p. 117) que ocorreu em 1867.

Com a Restauração Meiji, que recolocou o poder político nas mãos do Imperador, houve amplas transformações internas e também nas relações externas japonesas. O objetivo era desenvolver o país nas áreas econômica, social e tecnológica. Internamente, a economia japonesa que era basicamente agrícola durante a era Tokugawa, passa por um processo de industrialização, que foi importante para o fortalecimento e expansão militar do Japão e promoveu um deslocamento da mão-de-obra para os centros urbanos. A população passa por dificuldades causadas pelo empobrecimento dos proprietários rurais e da população urbana, que sofria com o desemprego estimulado também aumento demográfico e que o desenvolvimento da indústria manufatureira não foi capaz de amenizar. As populações das áreas rurais, que representavam cerca de $80 \%$ do total de empregado no Japão em 1880 (NOGUEIRA, 1973, p. 18), migraram para as cidades buscando novas oportunidades, acentuando o desequilibro entre a oferta e a procura por empregos.

No setor agrícola, a reforma tributária implementada em 1873 passou a exigir dinheiro e não mais produtos no pagamento tributário, isso dificultou a solvência da população e fez com que muitos lavradores perdessem parte significativa de suas propriedades no final do século XIX. Entre 1883 a 1990, 367 mil propriedades foram confiscadas em decorrência de processos contra os lavradores (NOGUEIRA, 1973, p. 23).

O desemprego e a pobreza foram agravados pelo aumento da população estimulado pela política do governo nacionalista Meiji que promoveu o aumento da taxa de natalidade no país, sob o slogan "Fukoku kyohei" ("Nação rica e militarmente forte") (ONOZAWA, 2003, p. 117). No período do Shogunato Tokugawa havia tolerância com relação a prática de aborto ou mesmo infanticídio para se manter o equilíbrio entre a população e os recursos disponíveis no país, na era Meiji o aumento da população passou a ser visto como algo importante, por isso, o governo adotou medidas para elevar o número da população, como organização médica hospitalar e vacinação entre outros auxílios (NOGUEIRA, 1973, p. 20).

Com o objetivo de tentar reduzir as tensões sociais no país, o governo de Tóquio passou a adotar uma política de realocação da população para áreas ao norte do país como 
Hokaido, ilhas Kurilas e Sakalinas. No entanto, os resultados não foram satisfatórios e a emigração transformou-se numa necessidade, fazendo com que políticas governamentais para transferir o excedente populacional ao exterior fossem iniciadas (ONOZAWA, 2003, p. 117). Associado a esse objetivo havia também o interesse em japonês em expandir a sua atuação internacional e criar condições para ampliação de mercado para seus produtos. Isso fez com que os interesses do Japão se projetassem para além das fronteiras regionais asiáticas e conduziu à busca de aproximação com o Brasil no final do século XIX.

\section{Política de emigração japonesa}

O século XIX e as primeiras décadas do século XX compreenderam um periodo de grande movimento migratório internacional. Embora as estimativas não sejam exatas por causa das incipientes condições de registros daquele periodo, há registros apontando que entre 70 a 75 milhões de pessoas tenham deixado seus países e se transferido para outros (LEÃO, 1990, p.7).

Esses fluxos migratórios podem ser divididos em dois grupos:

a) Primeiro, iniciado por volta de 1840 e que teve a contribuição importante de países como Irlanda, Reino Unido, Alemanha, França;

b) Segundo, foi o êxodo de pessoas ocorrido ao final do século XIX, envolvendo países como Itália, Espanha e Portugal, Rússia e Polônia e no qual se inclui o Japão. A maior contribuição foi de países Europeus, que corresponderam a aproximadamente $85 \%$ do total de emigrantes nesse período e a contribuição asiática foi significativamente menor.

Comparando-se as participações dos países entre meados da década de 1880 até meados da década de 1930, período de maior intensidade de movimentações, nota-se que o número total de emigrantes japoneses foi pequeno não atingindo 500 mil pessoas, enquanto foram quase três milhões de alemães, 10 milhões de italianos e 11 milhões de britânicos (LEÃO, 1990, p.8).

No período anterior a era Meiji, conforme mencionado, a imigração foi ainda mais restrita. Há registros que em 1868 emigraram 148 pessoas para o Havaí e 40 para Guam (AZUMA, s/d; MOFA, 1985). Esses imigrantes foram de forma ilegal e devido aos tratamentos recebidos pelos cidadãos japoneses nessas duas localidades - próximos ao de trabalho escravo -, o governo do Japão desautorizou novas saídas por praticamente duas décadas. Somente a partir de 1885, próximo à metade da Era Meiji (1868-1912), é que as autorizações para emigração foram oficializadas. Portanto, considerando-se que o maior número de emigrantes foi até a Segunda Guerra Mundial, história da emigração japonesa pode ser dividida em três fases (MCNAMARA \& COUGHLAN): 
i) Primeira, coincide com a Era Meiji (1868-1912)

ii) Segunda, ocorre na era Taisho (1912-1926)

iii) Terceira, inicia-se com a Era Showa (1926-1989) e vai até a Segunda Guerra Mundial.

A primeira fase de imigração oficial japonesa foi inaugurada com a ida de 945 pessoas para Havaí (TIGNER, 1981, p. 458), a primeira grande saída de pessoas do território, que foram contratadas para trabalharem na plantação e usinas de cana-de-açúcar. A emigração de japoneses para Havaí fora tão intensa que, atingiram 12.610 pessoas em 1890 e dez anos depois, em 1900, quando já somavam 61.111 imigrantes (ONOZAWA, 2003, p. 116 ), estes representavam aproximadamente $40 \%$ do total da população havaiana, que era de $154 \mathrm{mil}^{3}$. Até o final do século XIX os principais cinco principais países recebedores de imigrantes japoneses eram Havaí, Estados Unidos, Canadá, Austrália, México.

A imigração japonesa ganhou maior notoriedade a partir de 1893, com a Sociedade de Colonização - formada por oficiais de governo, políticos e intelectuais. Essa instituição, que estava sob a liderança do ex Ministro dos Negócios Exteriores, Takeaki Enomoto, tinha as ações colonizadoras dos países ocidentais como modelo. A partir de 1894, o governo japonês publicou a "Regulamentação de Proteção ao Emigrante" - Imin Hogo Kisoku, que delegava às companhias de emigração as funções de recrutamento, e em 1896, foi decretada a "Lei de Proteção Imigrante" Imin Hogoho (AZUMA, s/d) que regulava as atividades das companhias de emigração e protegia os interesses dos emigrantes (SAITO, 1961, p. 26). Com essas novas medidas, em 1898 já havia mais de 10 empresas funcionando com a finalidade conduzir emigrantes ao Havaí.

Um dos primeiros projetos da Sociedade de Colonização foi o estabelecimento de uma colônia agrícola com 28 imigrantes em Chiapas no México, em 1897. Apesar do fracasso da colônia, essa iniciativa marcou o início da imigração para a América Latina, e foi seguida de outro contrato de trabalho para 790 pessoas em 1899 para o Peru, e desses 91 foram redirecionados para a Bolívia (AZUMA, s/d).

A segunda fase da imigração ocorre na Era Taisho (1912-1926), período em que já ocorriam resistências internacionais ao recebimento de japoneses. Nos EUA os cidadãos americanos contestavam a entrada desses imigrantes, acusados de se submeterem, muitas vezes, a condições extremas e, com isso, contribuírem para a redução dos valores dos salários. Num círculo vicioso, a diminuição nos ganhos motivava os japoneses a não participarem

2. President McKinley signed the resolution of annexation on July 7, 1898. Disponivel em: http://www.hawaiian-roots.com/monarchy.htm. Acessado em 12/Out/08

3. Hawaiian Historical Society. Censuses. Disponível em: http://hawaiianhistory.org/moments/censuses.html. Acessado em 10/out/08 
das greves para obterem ganhos extras e, isso, acirrava ainda mais os descontentamentos dos americanos (NOGUEIRA, 1973, p. 33).

A resistência às imigrações japonesas estava presentes também no México, Canadá, Austrália e África do Sul (TIGNER, 1981, p. 459). Na América Central, a Costa Rica já havia imposto restrições em 1896, sob argumento do perigo amarelo que ameaçava os empregos dos trabalhadores locais, preocupação que motivou medidas semelhantes na Guatemala em 1909. Essas ações forçaram o redirecionamento dos cursos das naus para a América do Sul, particularmente para o Peru e Brasil, pois países como Paraguai, Colômbia entre outros (NOGUEIRA, 1973, p. 34) também tinham restrito a entrada de japoneses.

A terceira fase da imigração japonesa que coincide com a Era Showa (19261989), foi o período com maior regularidade nos fluxos de japoneses ao Brasil. $\mathrm{Na}$ fase anterior houve certa instabilidade causada, principalmente, pelo interesse dos japoneses em ingressarem nos EUA e pela irregularidade do apoio do governo paulista na vinda de novos trabalhadores. Mas na terceira fase, o envolvimento direto do governo japonês gerou um fluxo continuo e crescente de imigrantes japoneses ao Brasil até meados da década de 1930. Esse processo foi interrompido pela Segunda Guerra Mundial, mas é retomado, em menor escala, após o final da Segunda Guerra Mundial, continuando até a década de 1970.

\section{Imigração para o Brasil}

O Brasil com promulgação da lei áurea em 13 de maio de $1889^{4}$ passou a sofrer falta de mão-de-obra na lavoura, motivando a realização de vários acordos de imigração com países europeus e, particularmente, a Itália forneceu uma grande quantidade de trabalhadores para as fazendas de café. Em 1902, contudo, o governo italiano impôs restrições à vinda de mais imigrantes ao Brasil, o que talvez não teria uma grande repercussão sobre o país, caso não houvesse a retomada da dinâmica da lavoura cafeeira em 1903, conduzindo novamente à busca por mais mão-de-obra.

Esses fatos contribuíram para o surgimento da oportunidade para a imigração japonesa. $\mathrm{Na}$ realidade, em 1894 já houvera uma primeira tentativa de trazer imigrantes japoneses ao Brasil, "quando a firma Kichisa-Imin Kaisha, especializada em imigração entra em contato com a firma Prado Jordão, de São Paulo" (REZENDE, 1991, p.34). Contudo, ainda não havia um acordo entre os dois países que pudesse fundamentar tal empreendimento, apesar da vinda de Sho Nemoto, comissário do Ministério das Relações Exteriores do Japão, ao país em 1893. Essa visita que incluiu alguns Estados, entre eles, Bahia, Minas Gerais, Pernambuco, São

4. Esse ano foi importante ao Japão pela promulgação da sua Constituição de Meiji. 
Paulo (NAKASUMI \& YAMASHIRO, 1992), foi resultante do interesse japonês em expandir suas relações para fora da região asiática. As boas impressões do comissário favoreceram a aproximação entre os dois países, e contribuíram para que no dia 5 de outubro de 1895 , em Paris, ocorresse a assinatura do Tratado de Amizade, Comércio e Navegação formalizando o início das relações Brasil-Japão.

Desde então, as relações nipo-brasileiras têm se diversificado e ampliado. Iniciadas pelos fluxos migratórios, essa história não ocorreu sem dificuldades. Em 1901, houve outra tentativa de imigração, mas mesmo contando com a participação do Ministério das Relações Exteriores do Brasil, refletindo a resistência à imigração japonesa não se obteve sucesso. Manuel Oliveira Lima, Ministro Plenipotenciário do Brasil no Japão citado por Valdemar Carneiro Leão (1990, p. 22) afirma que a "imigração [japonesa] parece-me pouco desejável tanto pelo perigo que oferece de uma maior mistura de raças inferiores na nossa população, como pela carência de experiências agrícolas com modernos processos e utensílios que existe entre a população rural destes países asiáticos" Esse sentimento expressado por Oliveira Lima e a crise cafeeira no Brasil naquele período somaram-se ao fato do Japão ter focado a imigração inicialmente ao México e ao Peru, adiando a vinda dos japoneses ao país.

Do lado japonês, entretanto, o relatório escrito em junho de 1905, por Fukashi Suguimura, ministro plenipotenciário no Brasil, demonstrava otimismo para uma imigração japonesa para o Brasil. Ele avaliou como positiva a imigração italiana ao país e acreditava que a interrupção da imigração italiana faria com que os brasileiros recebessem os japoneses de braços abertos. Em seu relatório assinala que haveria dificuldades, mas elas seriam superadas.

"A despeito das declarações que o japonês não se adaptaria às condições de solo e idioma, tenho a exemplificar que os imigrantes italianos aqui aportaram. passaram por mil dificuldades e situações de extrema pobreza e nem por isso foram mal sucedidos. Ao contrário, vários deles já são donos de terras e podem manter suas familias" (KOYAMA, 1949 apud REZENDE, 1991, p. 19)

No início do século XX fortaleceram os estímulos econômicos para que se iniciasse a imigração nipônica ao país. Conforme já mencionado, do lado brasileiro houve a retomada da dinâmica da lavoura cafeeira em 1903, elevando a demanda por mão-de-obra, e do lado japonês, as dificuldades econômicas decorrentes da Guerra Russo-Japonesa de 1904-05 faziam com que o interesse pela emigração ganhasse impulso.

O Itamaraty via grandes riscos ao país por temer enfrentar dificuldades semelhantes aos EUA com a imigração japonesa, mas Carlos Botelho, Secretário de Agricultura de São Paulo, mais preocupado com o suprimento da mão-de-obra para a lavoura cafeeira, enviou em abril de 1908 um documento ao representante do Brasil em Tóquio, para tranqüilizar os diplomatas. Botelho afirmava que a utilização da mão-de-obra não significava uma colonização japonesa (LEÃO, 1990, p. 27). 
Como os fatores econômicos preponderaram, em 18 de junho de 1908 chegou o navio Kasato Maru ao porto de Santos trazendo a bordo 781 pessoas, marcando o início da imigração japonesa ao país. Foi também o início do período de adaptação entre os povos das duas nações, com tensões provocadas entre outros fatores, pelo choque entre duas culturas bastante diversas e pelas desilusões dos imigrantes em relação aos ganhos econômicos. (LEÃO, 1990, p. 28).

\section{Problemas dos imigrantes japoneses no Brasil}

A maioria dos imigrantes japoneses, de fato quase a totalidade, que chegou ao Brasil no período pré Segunda Guerra Mundial, tinha a expectativa de economizar dinheiro e regressar ao Japão. Por isso, havia a preocupação de não apenas preservar as raízes culturais, mas formar o japonês em terras brasileiras. Com essa finalidade se esforçaram para construírem escolas onde realizariam a transmissão da língua e da cultura de seu país de origem. Essa determinação, entretanto, fortalecia, por vezes, os sentimentos de desconfianças existentes na sociedade que os acolhiam. Além disso, nos anos 1930, também pesou contra a uma maior integração do nikkei na sociedade brasileira o nacionalismo brasileiro (MIYAO, 2002, p. 24). E, neste artigo, busca-se fazer uma avaliação da inserção dos imigrantes e descentes na sociedade brasileira pelas perspectivas social e econômica.

\section{a) Perspectiva Social}

A inserção e adaptação dos imigrantes japoneses no Brasil foram beneficiadas pelo fato de terem vindo em família exigência feita pelo governo do Estado de São Paulo, que entendia que dessa forma haveria menor risco de fugas (REZENDE, 1991, p.13). Essa característica foi decisiva para "evolução do grupo japonês, garantindo: crescimento populacional normal; continuidade das gerações e uma relativa estabilidade da vida familial; transmissão de cultura devido à presença de geração intermediária" (SAITO, 1980, p.82), tudo isso ajudando na preservação da cultura japonesa no Brasil.

De acordo com o Censo de 1920 , os japoneses representavam $0,09 \%$ da população brasileira total (30,1 milhões de habitantes). Nos anos seguintes, poderia ter ocorrido uma redução do fluxo da imigração por causa da suspensão dos subsídios fornecidos pelo governo do Estado de São Paulo. No entanto, observa-se uma aceleração, esse ato foi decorrente das subvenções à companhia Kaigai Kogyo Kabushiki Gaisha (KKKK) pelo parlamento japonês, em 1921 e da aprovação de 220 mil ienes pelo Departamento de Negócios Interiores do Japão, em 1923, para apoio à campanha de incentivo à imigração para o Brasil (LEÃO, 1989, p.30). 
Esse crescimento no número de imigrantes japoneses trouxe também um aumento da demando por serviços de educação que, devido à incapacidade do Estado brasileiro em fornecê-lo de forma adequada, levou ao estabelecimento de escolas japonesas. Estas serviam como um instrumento para transmissão da língua, da cultura e de valores religiosos, pois "além das atividades de cunho propriamente intelectual, as escolas passaram aos poucos a transformar-se em centros de doutrinação nacionalista, com exaltação dos valores básicos da niponicidade" (LEÃO, 1989, p.69).

Essas ações, se por um lado favoreciam a manutenção da cultura japonesa, geravam um ambiente de baixa integração na sociedade brasileira e mantinham dificuldades de comunicação, contribuindo para a forte resistência aos japoneses. Fato que perdurou, de maneira geral, até a primeira metade do século XX. Em 1923, o discurso de Fidélis Reis, deputado estadual de Minas Gerais, refletia essa resistência:

"na hipótese, sempre preferível de não se cruzar, permanecerá o amarelo enquistado no organismo nacional, inassimilável que é ele pelo sangue, pela língua, pelos costumes, pela religião, constituindo um perigo futuro, como na Califórnia para os Estados Unidos" (REIS, 1923, apud LEÃO, 1989, p. 35).

$\mathrm{Na}$ década de 1930, a mencionada instalação de escolas para japoneses e as manifestações de identidade étnica e cultural agravavam as desconfianças sobre os imigrantes (LEÃO, 1989, p.68). O governo Vargas foi um período em que as resistências à imigração japonesa se manifestaram de maneira concreta. Na Assembléia Nacional Constituinte de 1933-34, o pronunciamento de Miguel Couto na sessão de 27 de fevereiro de 1934, demonstra essa oposição:

“essa imigração representa uma fase, um estágio do expansionismo japonês. $O$ expansionismo japonês, aquilo que Mussolini chamou "o imperialismo dinâmico do Japão" segue uma ordem invariável - infiltração, esfera de influencia, absorção; ou se preferirem, invasão, ocupação ..." (LEÃO, 1989, p.320).

Com a chegada do Estado Novo as dificuldades aos estrangeiros no Brasil se ampliam.

"Por meio de uma série de decretos, o governo federal efetivou a partir de 1938, a campanha de nacionalização, que determinava a obrigatoriedade do uso da lingua portuguesa nas escolas étnicas, em atividades públicas, como comércio $e$ serviços religiosos ... particularmente em relação à comunidade japonesa, essas determinações levaram ao fechamento de suas escolas e de seus órgãos de imprensa" (TAKEUCHI, 2008, p.39).

A Segunda Guerra Mundial reduziu ainda mais as possibilidades de manifestações culturais japonesas. 
Esses fatos demonstram que houve uma inserção de trabalhadores japoneses na sociedade brasileira, mas a integração era deficiente e a não havia assimilação até a primeira metade do século XX. Ao contrário, o predomínio era de preocupação com as reações da sociedade brasileira às manifestações culturais japonesas. De acordo com Pereira (2004, p.513), "no princípio, embora houvesse garantias legais à liberdade de culto no Brasil, a propagação das religiões nipônicas foi inibida pelas autoridades japonesas - pretendendo evitar com isso que o imigrante fosse vítima de repúdio e hostilidade - e pelo meio brasileiro sob a hegemonia católica"

\section{b) Perspectiva Econômica}

A situação econômica do imigrante não era satisfatória desde o início, chegando ao ponto de Ryu Mizuno, fundador da companhia Koukoku Shokumin Gaisha (Companhia de Emigração Imperial) que trouxe os primeiros japoneses ao Brasil no Kasato Maru, enfrentar um clima de revolta entre os imigrantes, que armados com lanças de bambu, enxadas e foices (REZENDE, 1991, p.64). Cerca de dois meses depois da chegada ao país os imigrantes japoneses no Brasil apresentavam as seguintes preocupações:

" $\left.1^{\circ}\right)$ Chegaram ao Brasil quando a metade da colheita do café já havia sido feita, ... o ganho também não chegava para suprir as necessidades da familia e muito menos para pagar os empréstimos feitos no Japão, a juros elevadíssimos, para poder imigrar.

$\left.2^{\circ}\right)$ Dificuldades de adaptação à língua, ao clima e à culinária ...

$\left.3^{\circ}\right)$ O sistema de quase escravidão existente na maioria das fazendas ..., acordandoos às 4 da manhã com bater do sino. O trabalho se estendia até o por do sol ..

$\left.4^{\circ}\right)$ A escolha dos imigrantes. Na verdade, nem todos eram agricultores ... não afeitos ao trabalho no campo" (REZENDE, 1991, p.64)

Os sonhos de sucesso estavam longe da realidade vivida pelos imigrantes, em agosto de 1908 já havia pessoas vindas no primeiro grupo do Kasato Maru que queriam deixar o Brasil. Diante dessa situação, a iniciativa de imigração foi avaliada com um fracasso e o governo de São Paulo, que havia financiado a viagem, resolveu reduzir o número de imigrantes por ano de 1000 para 650 (REZENDE, 1991, p.66).

Com o passar dos anos, percebendo que o sucesso econômico não seria alcançado, começaram as ações de empreendedorismo dos imigrantes pela aquisição de terras no interior do Estado de São Paulo, cuja meta era de se tornarem agricultores independentes (SAKURAI, 2007, p.247). A oportunidade de aquisição surge com a ampliação da estrada 
de ferro por terras virgens, que precisavam ser desmatadas para permitirem a plantação de café. Essas novas localidades tinham preços muito baixos pela necessidade de preparação e também porque eram ainda ocupadas por índios.

Um segundo momento de expansão das compras de terras por imigrantes japoneses ocorreu depois da crise de 1929, que derrubou o preço internacional do café e fez com que muitos fazendeiros se desfizessem de parte de suas propriedades. Rezende (1991, p. 68) relata ainda que dois anos após o desembarque no Brasil alguns dos imigrantes já viviam na zona urbana trabalhando como "garçons, copeiros e cozinheiros [eram] disputadíssimos [com] a fama de serem honestos, sérios, cumpridores de sua obrigação e, sobretudo, por terem educação e cultura. Estes não só tinham encontrado uma nova inserção econômica como também já tinham incorporados alguns hábitos brasileiros, por exemplo, já consumiam café e comidas mais gordurosas e passaram a dormir em camas.

A partir de sucessos econômicos na agricultura, os empreendimentos começaram a se diversificar nas cidades, buscando ampliar os ganhos econômicos por meio do comércio. Esse processo não é imediato, muitas vezes exigiram um período de transição. "Há alternância da ocupação agrícola e não-agrícola, sempre a primeira servindo de apoio a segunda. Recorre-se, especialmente, à lavoura de arrendamento, sempre que há falta de capital e necessidade de poupança" (CARDOSO, 1998, p.61). Muitas iniciativas em setores não-agrícolas buscavam preservar alguma relação com a experiência obtida na área rural.

"Primeiramente, dedicavam-se às atividades que de mais perto se ligavam à agricultura: compradores de cereais, corretagem de imóveis rurais, armazéns se secos e molhados, botequins e pensões, oficinas de implementos agrícolas. Entre os bem-sucedidos, alguns conseguem montar máquinas de beneficiar arroz, café, algodão e outros produtos" (SAITO, 1980, p.86).

A partir da década de 1930 a produção agrícola dos imigrantes japoneses começa a ganhar visibilidade. Há a introdução de produtos alternativos ao café, como arroz e batata para serem vendidos nas cidades, que com o desenvolvimento da economia brasileira estavam em expansão. Outro produto que ganhou destaque nesse período foi o algodão, de cultivo mais fácil e rápido, que era fornecido para as empresas têxteis paulistas (SAKURAI, 2007, p.248). Nessa década a importância relativa da população nikkei na lavoura já era considerável, (LEÃO, 1989, p.58) e não era vista com bons olhos pelos brasileiros. Contribuiu para essa visão, por exemplo, a criação de infraestruturas, já mencionadas, que alimentavam as certezas de que haveria um plano imperialista de ocupação do território brasileiro do pelo Japão (TAKEUCHI, 2008, p.42). 


\section{TABELA 1}

Participação da produção dos imigrantes e seus descendentes na produção total Estado de São Paulo - Safra 1931-1932

\begin{tabular}{|l|c|c|c|}
\hline Chá & $75,0 \%$ & Bananas & 11,3 \\
\hline Legumes & $70,0 \%$ & Arroz & 8,0 \\
\hline Casulos de bicho da seda & $57,0 \%$ & Café & 5,0 \\
\hline Algodão & 46,4 & Feijão & 4,6 \\
\hline Batatas & 14,0 & Milho & 4,0 \\
\hline
\end{tabular}

Fonte: MAURETTE, Fernand. Alguns aspectos sociais do desenvolvimento atual e futuro da economia brasileira. Revista Brasileira de Imigração e Colonização, 9(1), Mar/1948. p.47-89. (Apud LEÃO, Valdemar Carneiro. $A$ crise da imigração japonesa no Brasil (1930-1940): contornos diplomáticos. Brasília: Fundação Alexandre de Gusmão, 1989).

O período de restrições contra a imigração japonesa perdura até final dos anos 1940, mas já nos primeiros anos da década de 1950 as tensões bilaterais reduzem de maneira significativa, há a retomada das relações Brasil-Japão e foi permitida a volta de publicações em japonês (SAITO, 1980, p. 86).

\section{Mudanças depois da segunda guerra mundial}

Depois da Segunda Guerra Mundial, a imagem dos imigrantes japoneses perante os brasileiros sofreu importantes transformações, e o novo perfil de relacionamento entre os dois países está entre os fatores que podem ter contribuído isso. Até o começo da década de 1950, a renda per capita no Japão era inferior a US\$ 180 enquanto no Brasil já era acima de US\$250 (YOKOTA, 1996, p.30), motivando uma retomada da imigração ao Brasil. Entretanto, nos anos 1950, iniciaram-se também os fluxos de investimentos diretos estrangeiros (IDE) japoneses ao país, tendo como um grande marco desse período a Usina Siderúrgica de Minas Gerais.

As relações econômicas entre os dois países aceleraram após a Segunda Guerra Mundial. No Brasil a presença de capital japonês "até 1955 eram apenas de seis empresas, no período de cinco anos entre 1956 a 1960 aumentaram para trinta e cinco empresas. Casos representativos eram as empresas de tecelagem como Toyobo Co. Ltd, Kanebo Co. Ltd, e outras como o estaleiro Ishikawajima, Toyota Motor Corp, Yanmar Diesel Engine Co. Ltd, Howa Machinery, NGK Spark Plug Co. Ltd" (HORISAKA, 1997, p.75). Esses investimentos convergiam com os interesses de industrialização do Brasil. 
Outros dois fatos que parecem ter influenciado a nova imagem do nikkei no Brasil foram:

a) Os Estados Unidos modificarem sua relação com o Japão no pós Segunda Guerra, particularmente, a partir do momento em que as forças comunistas, liderada por Mao Tse Tung, passam a ganhar espaço político na China foi outro fator e,

b) A rápida recuperação da economia japonesa, nesse mesmo período, gerou admiração nos brasileiros e maior aceitação de influencias culturais japonesas.

Um exemplo dessa maior receptividade foi a disseminação da religião japonesa no país. Paiva (2005) cita que Seicho-no-iê chegou ao Brasil por volta de 1950 e a Perfect Liberty em 1957 e Gonçalves (2008, p.2) relata que a Igreja Messiânica Mundial "foi introduzida em 1955 através do trabalho dos missionários Minoru Nakahashi e Nobushiko Shoda"

Além da entrada de IDE japoneses e da recuperação da economia japonesa, "os produtos japoneses, supostamente melhores que os de fabricação nacional, fizeram com que muitos brasileiros associassem essa mesma qualidade aos nipo-brasileiros" (LESSER, 2008, p.50), contribuindo para que ganhassem uma percepção positiva. A melhoria do ambiente no Brasil para o nikkei coincide com a consolidação de alguns de empreendimentos econômicos importantes, cujos alguns exemplos foram apresentados no trabalho de Deliberador (2000) e na premiação dos descendentes de japoneses empreendedores de sucesso, homenageados no dia 4 de julho de 2008 pela Revista Exame. Note-se que com exceção do Grupo Maeda e do empresário Itimura, todos os demais apresentam uma história iniciada na década de 1940 em diante.

\section{TABELA 2}

\section{LISTA DE HOMENAGEADOS PELA REVISTA EXAME}

\begin{tabular}{|c|c|c|c|}
\hline Chieko Aoki & Blue Tree Hotels & Hotelaria & 1992 \\
\hline Família Kitano & Yoki Alimentos & Indústria de Alimentos & 1960 \\
\hline Família Kurita & Hikari & Indústria de Alimentos & 1965 \\
\hline Família Maeda & Grupo Maeda & Agra-Indústria & 1932 \\
\hline Família Nakaya & Sakura Nakaya Alim. & Indústria de Alimento & 1940 \\
\hline Família Sasazaki & Sasazaki; & Indústria de Esquadrias & 1943 \\
\hline Família Takaoka & Y.Takaoka Empreend. & Construção Civil & 1951 \\
\hline Hideaki Iijima & Soho Hair International & Salão de Beleza & 1982 \\
\hline Ruy Ohtake & Ruy Ohtake Arquit. e Urbanismo & Escritório de Arquitetura & 1960 \\
\hline Satoshi Yokota & Vice-presidente Exec. Embraer & Indústria de Aviões & 1970 \\
\hline Shunji Nishimura & Jacto & Indústria de Equipam. & 1948 \\
\hline
\end{tabular}

Fonte: Exame homenageia empresários nipo-brasileiros. Disponível em: http://japaol00.abril.com.br/arquivo/ exame-homenageia-empresarios-nipo-brasileiros/. Acesso em 5/Jun/2008. Elaboração do autor. 


\section{Considerações finais}

Como se pode perceber ao longo do texto, no início da imigração japonesa ao Brasil, nem os imigrantes nem os brasileiros pensavam numa integração. Os primeiros planejavam regressar à terra do "Sol Nascente", já os segundos temiam a inclusão no seio da sociedade brasileira por problemas que poderiam decorrer dessa tentativa, por causa das diferenças culturais ou até mesmo por um temor de invasão japonesa. No entanto, com o passar do tempo, ambas as perspectivas vão se alterando conduzindo a inserção diferenciada.

No caso dos imigrantes a instabilidade nas relações internacionais marcada pelas duas Guerras Mundiais fez com que os planos de regresso ao Japão fossem abortados e a odisséia da imigração japonesa no Brasil ganhasse novos rumos. Ao invés de objetivar o retorno ao país de origem, passaram a procurar adaptação à sociedade brasileira. No caso do Brasil, a nova relação de Tóquio com Washington e o desempenho econômico japonês fizeram com que o perfil do relacionamento se alterasse no período do segundo pós Guerra.

Com isso, houve uma mudança no ambiente em solo brasileiro ao nikkei, que buscando qualificação profissional passou a ocupar $10 \%$ das vagas nas universidades no período de 1960-1970, apesar de representarem apenas 2\% da população do Estado de São Paulo. Essa maior presença em ensino superior conduziu a uma participação em algumas profissões, maior que a representação na população. Por exemplo, já na década de 1970 eles representavam $11,8 \%$ dos profissionais da área química, $9 \%$ da área econômica $\mathrm{e}$ $8 \%$ da odontológica. Em 1977 cerca de 5\% de todos os professores universitários de São Paulo eram de ascendência japonesa. Houve também uma mobilidade social importante, que pode ser entendido como corolário da formação educacional. Segundo o Relatório PNAD do IBGE de 1988 os brasileiros de origem asiática (majoritariamente descendentes de japoneses) situavam-se no topo da pirâmide social. Tendo uma renda "cerca de $76 \%$ maior que os brasileiros de origem européia e 4,3 vezes maior que os brasileiros de origem africana" (SHOJI, 2002, p.62).

A integração do nikkei na sociedade brasileira abrange também a política, passando a ascender cargos públicos. Alguns são: Fábio Riodo Yassuda, nomeado ministro da Indústria e Comércio em 1969; Shigueo Watanabe, nomeado para o Conselho Nacional de Pesquisa em 1971; Shigueaki Ueki que foi Ministro das Minas e Energia (1974-1979) e presidente da Petrobras; recentemente o Brasil teve Luis Gushiken, como ministro da Comunicação de Governo e Gestão (2003-2005). Esses são alguns exemplos, mas já é grande o número de políticos nikkei no Brasil ocupando diferentes cargos em todo o país.

Esses dados mostram que há uma maior integração do nikkei no Brasil, inclusive com uma imagem muito distante do que foi no início da história da imigração. Um fato que corrobora com essa interpretação é o fato da empresa Semp Toshiba nos anos 1990 utilizarem- 
se da frase "Os nossos japoneses são mais criativos do que os japoneses dos outros" De acordo com José Eustachio, sócio-diretor da Talent, empresa que criou esse slogan, a frase "não apenas destacou a Semp Toshiba em relação às suas concorrentes como criou um subsegmento na categoria de televisores: o das marcas japonesas" (HORVATH, 2008).

Esse comercial mostra que desde o final do século XX há uma inserção muito mais positiva do nikkei no Brasil do que no início do século, no entanto, o fato de se usar a referência "nossos japoneses" corrobora com a interpretação de Lesser (2008) de que há dois movimentos que se apresentam contraditórios, o nikkei buscando mostrar sua brasilidade, enquanto a sociedade brasileira buscar reforçar a niponicidade. No ano de 2008, a mídia fez uma grande cobertura ao longo do ano sobre o centenário da imigração japonesa no Brasil. E o interessante a ser notado é que foram dados destaques principalmente àquilo que o nikkei é "japonês", ainda que tenha nascido e crescido no Brasil.

Portanto, pode-se se concluir que houve muitas transformações ao longo do século de história da imigração japonesa no Brasil, mas o debate sobre a identidade e a interação da entre as duas culturas, japonesa e a brasileira, continua sendo um tema proficuo.

Bibliografia

AZUMA, Eiichio. Brief Historical Overview of Japanese Emigration, 1868-1998. Disponivel em: http://www.discovernikkei.org/wiki/index.php/Brief_Historical_ Overview_of_Japanese_Emigration,_1868-1998\#Brief_Historical_Overview_of_ Japanese_Emigration.2C_1868-1998. Acessado em 12/Out/08

HALL, Stuart. A identidade cultural na pós-modernidade. Rio de Janeiro: DP\&A, 2003. HORISAKA, Kotaro. "Alvorada das relações econômicas nipo-brasileiras" In: YOKOTA, Paulo. Fragmentos sobre as relações nipo-brasileiras no pós-guerra. Rio de Janeiro: Topbooks, 1997

HORVATH, Sheila. Um casamento de culturas na publicidade. Gazeta Mercantil, 14 de Julho de 2008. Caderno C - Pág. 8. Disponível em: http://www.abert.org.br/D_mostra_ clipping.cfm?noticia $=118407$. Acessado em $12 /$ Nov/08

ITOH, Mayumi. Japan's abiding Sakoku mentality. Orbis: A Journal of World Affairs. Vol. 40, Spring, 1996, p. 235-245.

KOYAMA, Rokuro. A história dos 40 anos de imigração japonesa no Brasil. São Paulo, 1949.

LEÃO, Valdemar Carneiro. A crise da imigração japonesa no Brasil (1930-1934): contornos diplomáticos. Brasília: Fundação Alexandre de Gusmão, 1989. 
LESSER, Jeffrey. Uma diáspora descontente: os nipo-brasileiros e os significados da militância étnica 1960-1980. São Paulo: Paz e Terra, 2008. P.293.

MCNAMARA, Deborah J. and COUGHLAN, James E. Recent Trends in Japanese Migration to Australia and the Characteristics of Recent Japanese Immigrants Settling in Australia. Disponível em: http://www.faess.jcu.edu.au/saas/downloads/ JimCoughlan/31-92jap.htm. Acessado em 12/Out/08

MINISTRY OF FOREIGN AFFAIRS. Diplomatic Bluebook 1985 Edition. Review of Recent Developments in Japan's Foreign Relations. Section 5. One Hundred Years of Government-endorsed Emigration. Disponivel em: http:/www.mofa.go.jp/policy/ other/bluebook/1985/1985-3-5.htm. Acessado em 12/Out/08

MIYAO, Susumu. Nipo-brasileiros - processo de assimilação. São Paulo: Centro de Estudos Nipo-brasileiros, 2002. p. 269.

MORISHIMA, Michio. Why Has Japan Succeeded? Western Technology and the Japanese Ethos. Cambridge University Press, Cambridge, U.K. 1989

NAKASUMI, Tetsuo \& YAMASHIRO, José. "Fim da Imigração e Consolidação da Nova Colônia Nikkei." pp.381-458. In: Uma Epopéia Moderna: 80 Anos da Imigração Japonesa no Brasil. (Comissão de Elaboração da História dos 80 Anos da Imigração Japonesa no Brasil). São Paulo: Hucitec/Sociedade Brasileira de Cultura Japonesa, 1992. 604p.

NOGUEIRA, Arlinda Rocha. A emigração japonesa para a lavoura cafeeira paulista (1908-1922). São Paulo: Instituto de Estudos Brasileiros, 1973.

ONOZAWA, Nitaya. Immigration from Japan to the U.S.A., Historical Trends and

Background. 2003. Disponivel em: http://www.tsukuba-g.ac.jp/library/kiyou/2003/7. ONOZAWA.pdf

REZENDE, Tereza Hatue de. Ryu Mizuno: A saga japonesa em terras brasileiras. Curitiba: SEEC; Brasília, INL, 1991. P.115p.

SAITO, Hiroshi (Org.). A presença japonesa no Brasil. São Paulo: Edusp, 1980.

SAITO, Hiroshi. O Japonês no Brasil: estudo de mobilidade e fixação. São Paulo: Editora Sociologia e Política, 1961.

SAKURAI, Célia. Os japoneses. São Paulo: Editora Contexto, 2007.

SHOJI, Rafael. O Budismo Étnico na Religiosidade Nikkey no Brasil: Aspectos Históricos e Formas de Sobrevivência Social. Revista de Estudos da Religião - REVER. Número 4 Ano 2 2002. Disponível em: http://www.pucsp.br/rever/rv4_2002/p_shoji.pdf. Acessado em 20/Jul/08

TAKEUCHI, Márcia Yumi. Os tempos amargos da perseguição. p. 39-45. In: História Viva: Japão. 500 anos de história: 100 anos de imigração. Vol. 3, São Paulo: Duetto Editorial, 2008. 
TIGNER, James. Japanese Immigration into Latin America: A Survey. Jornal of interamerican Studies and World Affairs, Vol. 23, number 4 (nov.,1981) pp. 457-482. Disponível em: http://links.jstor.org/sici?sici=00221937\%28198111\%2923\%3A4\%3C457\%3AJIILAA\%3E2.0.CO\%3B2-D. Acessado em 20/Set/07 